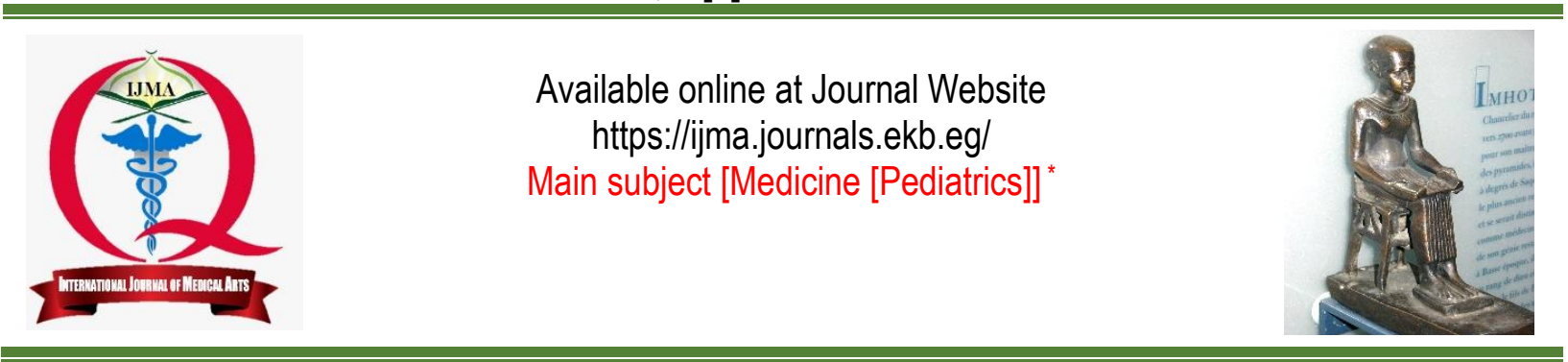

Original article

\title{
Inhaled Salbutamol for the Treatment of Transient Tachypnea of the Newborn
}

\author{
Ahmed Abdelaty Salama; Lotfy Abdel-Fattah El-Seheimy; Mohamed Ibrahim Elsamanoudy
}

Department of Pediatrics, Damietta Faculty of Medicine, Al-Azhar University, Egypt

Corresponding author: Ahmed Abdelaty Salama

Email: drahmedsalama@yahoo.com

Submitted at: December 29, 2019; Revised at: April 14, 2020; Accepted at: April 15, 2020; Available online at: April 15, 2020

\section{ABSTRACT}

Background: Transient tachypnea of the newborn [TTN] is a common physiologic lung disorder. Stimulation of $\beta$-adrenergic receptors could alleviate the condition.

Aim of the work: The study was undertaken to assess the efficacy and safety of inhaled salbutamol in reduction of TTN, oxygen treatment and hospitalization.

Patients and Methods: This clinical study included 150 [50 control group, 50 single dose of salbutamol and 50 double-doses of salbutamol] infants between $35^{\text {th }}-39^{\text {th }}$ week's gestation. Inhaled salbutamol was given and comparison between the three groups was carried out.

Results: Treatable and control groups were comparable as regard neonatal and maternal characteristics. Heart rate was significantly increased in group B when compared to control group half and one hour after treatment. In addition, respiratory rate was significantly increase in group $B$ when compared to group $A$ at half hour after treatment and continued till 8 hours after treatment. The TTN score after treatment was significantly lower in group B when compared to group $A$ at one hour after nebulized salbutamol and continued till 8 hours. Furthermore, time before initiation of feeding was significantly reduced in group B when compared to group $A[26.72[ \pm 3.68]$ vs $[39.66[ \pm 4.7]$ and also there was significant reduction of hospitalization days in group B when compared to group A [3.78 [ \pm 1.25$]$ vs $[7.36[ \pm 1.28]$.

Conclusion: Inhalational salbutamol reduced duration of supplemental oxygen therapy, the duration of hospitalization and time before initiation of feeding, and no adverse effects were reported. Thus, inhaled salbutamol seems to be effective and safe in TTN.

Keywords: Neonate; Salbutamol; Transient; Tachypnea; Nebulized

This is an open access article under the Creative Commons license [CC BY] [https://creativecommons.org/licenses/by/2.0/]

Please cite this article as: Salama AA, El-Seheimy LA, Elsamanoudy MI. Inhaled Salbutamol for the Treatment of Transient Tachypnea of the Newborn. IJMA 2020; 2[2]: 457-461.

\footnotetext{
* Main subject and any subcategories have been classified according to researchers' main field of study.
} 


\section{INTRODUCTION}

Transient tachypnea of the newborn [TTN] or wet lung is a common physiologic lung disorder characterized by pulmonary edema secondary to clearance delay of fetal alveolar fluid immediately after birth [1]. The exact incidence of TTN is unclear. It is estimated that $0.5 \%$ of newborns suffer from wet lung when they are born. According to some epidemiological studies, the incidence of TTN of fullterm newborns and premature infant's is $4-5.7 \%$ and $10 \%$, respectively. The main high-risk factors include cesarean section, large birth weight, maternal diabetes, maternal asthma, twins, male babies, apneic hypoxia, aspiration of amniotic fluid, over transfusion after birth, delayed umbilical cord ligation[2]

TTN management consists of supportive care, with symptoms generally resolving by 24 to 72 hours of age without significant morbidity. In addition, severe respiratory morbidity and mortality have been reported in some infants [i.e. hypoxia, respiratory distress, and pulmonary air leak], unnecessary antibiotic use, and parental anxiety. The main highrisk factors include cesarean section, large birth weight, maternal diabetes, maternal asthma, twins, male babies, apneic hypoxia, aspiration of amniotic fluid, over transfusion after birth, delayed umbilical cord ligation, patent ductus arteriosus [left-to right shunt and increased pulmonary blood flow increases hydrostatic pressure within blood capillaries of pulmonary vessels, which affects lung fluid clearance], hypoproteinemia , premature birth[3]

Salbutamol is a short-acting, selective Beta2adrenergic receptor agonist. increase epithelial sodium channel [ENaC] activity to promote lung fluid clearance and this regulates alveolar epithelial $\mathrm{Na}+$ transport by increasing the activity of epithelial $\mathrm{Na}+$ channels [ENaC] and $\mathrm{Na}+-\mathrm{K}+[4]$ The significant role of $B 2 A A$ in promoting resolution of alveolar pulmonary edema was suggested from animal studies and ex vivo human lung studies ${ }^{[5]}$. However, its use in treatment of management of TTN is not well covered in our institution.

\section{AIM OF THE WORK}

This study was to assess the efficacy and safety of inhaled salbutamol in reducing tachypnea, oxygen treatment, and hospitalization for infants with transient tachypnea of the newborn.

\section{PATIENT AND METHODS}

This study was conducted at Neonatal Intensive Care unit of Al-Azhar University Hospital [New Damietta] through the period from July 2018 till April 2019.The inclusion criteria were gestational age 35th-39th weeks gestation delivered by cesarean section or vaginal delivery and physical examination and radiologic findings suggesting TTN diagnosis. On the other hand, the newborns with the history of meconium aspiration, respiratory distress syndrome, congenital neonatal pneumonia, polycythemia, hypoglycemia, early sepsis, cardiac disorders, tachycardia [HR>180 b/min], cardiac arrhythmia, and congenital anomaly were excluded from the study.

In our study 150 neonates who were gestational age between 35th -39th week's gestation with TTN were randomly division into three groups the group [A] [control group] received nebulized dose of normal saline solution $0.9 \%$, oxygen and IV fluids. However, group $[B]$ received single nebulized dose of salbutamol $0.15 \mathrm{mg} / \mathrm{kg}$ in $0.9 \%$ saline in addition to oxygen and IV fluids. group [C] received double dose of salbutamo $0.15 \mathrm{mg} / \mathrm{kg}$ in $0.9 \%$ saline solution in addition to oxygen and IV fluids. TTN score before the treatment, 30 and $60 \mathrm{~min}$, and $4 \mathrm{~h}$ after nebulization [Table 1].

Table [1]: TTN clinical score. [5]

\begin{tabular}{|l|l|l|l|l|}
\hline Score & 0 point & 1 point & 2 points & 3 points \\
\hline Expiratory grunting & None & Intermittent & Continuous & ---- \\
\hline Supraclavicular retraction & None & Mild & Moderate & Severe \\
\hline Subcostal retraction & None & Mild & Moderate & Severe \\
\hline Cyanosis & None & At extremities & Central & ---- \\
\hline Nasal flaring & None & Mild & Moderate & Severe \\
\hline
\end{tabular}

Arterial blood gas measured 4 hours after the intervention. The duration of tachypnea, oxygen required, mechanical ventilation, continuous positive airway pressure support, hospital stay, and the time of starting enteral nutrition were observed to assess efficacy of treatment. In this study, all neonates were observed for tachycardia and arrhythmia. Tachycardia was known as heart beat more than 180 beats per minute.

Statistical analysis: Data were coded and entered using the statistical package SPSS version 20. Data was summarized using mean, standard deviation, median, minimum and maximum for quantitative variables and frequencies [number of cases] and relative frequencies [percentages] for categorical variables. Comparisons between groups were done using unpaired $t$ test when comparing 2 groups. Comparison between values measured 
before and after salbutamol in the same group was done using paired t test.

\section{RESULTS}

There was no a significant difference between the treatable and control groups in gender, gestational age, weight at birth, maternal history of asthma, delivery type, and $1^{\text {st }}$-and $5^{\text {th }}$-minute Apgar score. The lack of significant differences regarding demographic variables between the three groups [Table 2].

With regard to the quantitative nature of the data and their normal distribution, the repeated measure ANOVA was used to compare the means of respiratory and heart rates, Fio2, $\mathrm{O} 2$ saturation, and distress scores between the treatment and control groups at different time periods.

There was no statically significant difference in group A regarding HR before 126.8[ \pm 6.27$]$ and 4 hours after nebulized $128.8[ \pm 4.5]$ with $P=0.193$, there was no statically significant difference in group $B$ regarding HR before $132.4[ \pm 7.78]$ and 4 hours after nebulized $131.3[ \pm 4.52]]$ with $P=0.567$. And also, there was no statically significant difference in group $C$ regarding heart rate before $126.4[ \pm 7]$ and 4 hours after nebulized $129.28[ \pm 4.7]$ with $P=0.09$ [Table 3].
The mean values of the respiratory rate, and TTN score in before and after the initiation of the study was significantly decreased in salbutamol groups [P value $<0.001$ ]. [Tables 4 and 5].

In the salbutamol group the mean values of primary outcomes including duration of oxygen therapy [ $p$ value $<0.001$ ], duration of admission in hospital $[P$ value $=0.004]$ and time of starting of enteral feeding $[P<0.001]$ were significantly lower than in control group. There was statically significant difference between group $A$ and group $B$ as regard to Total Duration on oxygen in hours with $p$ value $<0.001$, Duration on nasal cannula in hours with $p$ value $<0.001$ and Duration on Head Box in hour with $p$ value $<0.001$. There was no significant difference between group $B$ and group $C$ as regard to total duration on oxygen in hour [Table 6]

No kinds of side effects of salbutamol were observed among the neonates since they were checked daily in terms of the $\mathrm{Na} / \mathrm{K}$ and blood sugar.

Potassium levels were significantly lower in group $B$ when compared to group $A$ at 4 and 8 hours, while the difference between groups $B$ and $C$ was statistically non-significant either at 4 or 8 hours [Table 7].

Table [2]: Comparison of demographic variables between two groups.

\begin{tabular}{|c|c|c|c|c|c|}
\hline \multirow{2}{*}{\multicolumn{2}{|c|}{ Variable }} & \multicolumn{2}{|c|}{ Treatment group } & \multirow{2}{*}{$\begin{array}{c}\text { Control group } \\
\text { Group C }\end{array}$} & \multirow[b]{2}{*}{$P$ value } \\
\hline & & Group A & Group B & & \\
\hline \multicolumn{2}{|l|}{ Maternal age [year] } & $29.84 \pm[4.06]$ & $26.84 \pm[4.1]$ & $28.04 \pm[4.17]$ & 0.080 \\
\hline \multicolumn{2}{|c|}{ Gestational Age [week] } & $38.36 \pm[0.76]$ & $38.48 \pm[0.87]$ & $37.9 \pm[0.89]$ & 0.040 \\
\hline \multicolumn{2}{|c|}{ Birth Weight $[\mathrm{Kg}]$} & $3.34 \pm[0.39]$ & $3.33 \pm[0.42]$ & $3.34 \pm[0.39]$ & 0.994 \\
\hline \multicolumn{2}{|c|}{ Skull Circumference $[\mathrm{cm}]$} & $34.16 \pm[0.85]$ & $33.9 \pm[0.53]$ & $33.8 \pm[0.66]$ & 0.264 \\
\hline \multicolumn{2}{|c|}{ Length $[\mathrm{cm}]$} & $49.28 \pm[1.29]$ & $49.76 \pm[1.27]$ & $49.44 \pm[1.55]$ & 0.541 \\
\hline \multirow[t]{2}{*}{ Sex } & Male & {$[26[52 \%$} & {$[24[48 \%$} & {$[22[44 \%$} & \multirow[t]{2}{*}{0.857} \\
\hline & Female & $24[48 \%]$ & $26[52 \%]$ & $28[56 \%]$ & \\
\hline \multirow[t]{2}{*}{ Mode of Delivery } & Vaginal & $12[24 \%]$ & $8[16 \%]$ & $8[16 \%]$ & \multirow[b]{2}{*}{0.713} \\
\hline & Cesarean section & 38 [76\%] & $42[84 \%]$ & $42[84 \%]$ & \\
\hline
\end{tabular}

Table [3]: Detailed Description of Heart rate Before and After Nebulized Salbutamol

\begin{tabular}{|l|c|c|c|c|c|c|}
\hline & \multicolumn{2}{|c|}{ Group A Compared to group B } & & \multicolumn{2}{c|}{ Group B Compared to group C } & \\
\hline & Group A & Group B & P value & Group B & Group C & P value \\
\hline At admission & $126.8[ \pm 6.27]$ & $132.4[ \pm 7.78]$ & 0.824 & $132.4[ \pm 7.78]$ & $126.4[ \pm 7]$ & 0.805 \\
\hline Half hour after administration & 126.4 & 131.36 & $\mathbf{0 . 0 1 2 ^ { * }}$ & 131.36 & 130.56 & 0.673 \\
\hline One hour after administration & $129.4[ \pm 4.09]$ & $136.36[ \pm 5.39]$ & $\mathbf{0 . 0 0 1 ^ { * }}$ & $136.36[ \pm 5.39]$ & $135.64[ \pm 4,82]$ & 0.784 \\
\hline Four hours after administration & $128.8[ \pm 4.50]$ & $131.36[ \pm 4.52]$ & 0.054 & $131.36[ \pm 4.52]$ & $129.28[ \pm 4,71]$ & 0.118 \\
\hline 6 hours after administration & $129[ \pm 4.09]$ & $128.41[ \pm 4.60]$ & 0.053 & $128.41[ \pm 4.60]$ & $130.12[ \pm 4,68]$ & 0.120 \\
\hline 8 hours after administration & $129.6[ \pm 4.08]$ & $130.26[ \pm 4.09]$ & 0.056 & $130.26[ \pm 4.09]$ & $130.73[ \pm 4,69]$ & 0.119 \\
\hline
\end{tabular}


Salama AA, et al.

Table [4]: Detailed Description of respiratory rate Before and After Nebulized Salbutamol

\begin{tabular}{|l|c|c|c|c|c|c|}
\hline & \multicolumn{3}{|c|}{ Group A Compared to group B } & \multicolumn{3}{c|}{ Group B Compared to group C } \\
\hline & Group A & Group B & & Group B & Group C & P value \\
\hline Before nebulized & $76[ \pm 5.97]$ & $73.24[ \pm 5.19]$ & 0.088 & $73.24[ \pm 5.19]$ & $75.32[ \pm 4.44]$ & 0.135 \\
\hline Half hour after nebulized & 74.2 & 71.44 & $\mathbf{0 . 0 1 5 ^ { * }}$ & 71.44 & 70.92 & 0.670 \\
\hline One hour after nebulized & $70[ \pm 4.04]$ & $66.72[ \pm 4.88]$ & $\mathbf{0 . 0 1 4}^{*}$ & $66.72[ \pm 4.88]$ & $66.64[ \pm 4.27]$ & 0.927 \\
\hline Four hours after nebulized & $76.28[ \pm 4.60]$ & $60.68[ \pm 3.86]$ & $<\mathbf{0 . 0 0 1 ^ { * }}$ & $60.68[ \pm 3.86]$ & $61.44[ \pm 3.91]$ & 0.407 \\
\hline 6 hours after nebulized & $76.40[ \pm 4.58]$ & $59.56[ \pm 3.84]$ & $<0.001^{*}$ & $59.56[ \pm 3.84]$ & $60.43[ \pm 3.87]$ & 0.403 \\
\hline 8 hours after nebulized & $76.15[ \pm 4.40]$ & $59.65[ \pm 3.82]$ & $<0.001^{*}$ & $59.65[ \pm 3.82]$ & $59.71[ \pm 3.85]$ & 0.401 \\
\hline
\end{tabular}

Table [5]: Detailed Description of TTN score Before and After Nebulized Salbutamol

\begin{tabular}{|l|c|c|c|c|c|c|}
\hline & \multicolumn{3}{|c|}{ Group A Compared to group B } & \multicolumn{3}{c|}{ Group B Compared to group C } \\
\hline & Group A & Group B & & Group B & Group C & P value \\
\hline Before salbutamol & $7.72[ \pm 0.89]$ & $7.68[ \pm 0,98]$ & 0.881 & $7.68[ \pm 0,98]$ & $7.76[ \pm 0,59]$ & 0.731 \\
\hline 30 min after nebulized & 7.48 & 7.08 & 0.109 & 7.08 & 7.12 & 1.000 \\
\hline One hour after nebulized & $6.48[ \pm 0.51]$ & $5.84[ \pm 0.94]$ & $\mathbf{0 . 0 0 5 ^ { * }}$ & $5.84[ \pm, 94]$ & $5.84[ \pm, 85]$ & 1.000 \\
\hline Four hours after nebulized & $7.6[ \pm 1]$ & $4.28[ \pm 1.13]$ & $<.001^{*}$ & $4.28[ \pm 1,13]$ & $4.56[ \pm 1,04]$ & 0.369 \\
\hline 6 hours after nebulized & $7.5[ \pm .87]$ & $4.26[ \pm 1.17]$ & $<.001^{*}$ & $4.26[ \pm 1,17]$ & $4.54[ \pm 1,03]$ & 0.360 \\
\hline 8 hours after nebulized & $7.6[ \pm .88]$ & $4,25[ \pm 1.16]$ & $<.001^{*}$ & $4,25[ \pm 1,16]$ & $4,55[ \pm 1,04]$ & 0.401 \\
\hline
\end{tabular}

Table [6]: Level of Respiratory Support and $2^{\text {nd }}$ outcome For Studied groups.

\begin{tabular}{|c|c|c|c|c|c|c|c|}
\hline & \multicolumn{3}{|c|}{ Group A Compared to group B } & \multicolumn{3}{|c|}{ Group B Compared to group C } \\
\hline & & \multirow{2}{*}{$\begin{array}{c}\begin{array}{c}\text { Group A } \\
{[\mathrm{n}=50]}\end{array} \\
\text { Count [\%] }\end{array}$} & \multirow{2}{*}{$\begin{array}{c}\text { Group B } \\
{[\mathrm{n}=50]} \\
\text { Count [\%] }\end{array}$} & \multirow[t]{2}{*}{$\begin{array}{c}P \\
\text { value }\end{array}$} & $\begin{array}{l}\text { Group B } \\
{[n=50]}\end{array}$ & $\begin{array}{c}\text { Group C } \\
{[n=50]}\end{array}$ & \multirow[t]{2}{*}{$\begin{array}{c}P \\
\text { value }\end{array}$} \\
\hline & & & & & Count [\%] & Count $[\%]$ & \\
\hline \multirow{2}{*}{$\begin{array}{l}\text { Level of Respiratory Support } \\
\text { [after } 30 \mathrm{~min} \text { ] }\end{array}$} & CPAP & $24[48 \%]$ & $28[56 \%]$ & \multirow[t]{2}{*}{0.772} & $28[56 \%]$ & $22[44 \%]$ & \multirow[t]{2}{*}{0.572} \\
\hline & Nasal & $26[52 \%]$ & $22[44 \%]$ & & $22[44 \%]$ & $28[56 \%]$ & \\
\hline \multirow{2}{*}{$\begin{array}{l}\text { Level of Respiratory Support } \\
\text { [after1hour] }\end{array}$} & CPAP & $20[40 \%]$ & 14 [28\%] & \multirow[t]{2}{*}{0.769} & $14[28 \%]$ & 18 [32\%] & \multirow[t]{2}{*}{1.00} \\
\hline & Nasal & $30[60 \%]$ & $36[72 \%]$ & & $36[72 \%]$ & $32[64 \%]$ & \\
\hline \multirow{2}{*}{$\begin{array}{l}\text { Level of Respiratory Support } \\
\text { [after } 4 \text { Hours] }\end{array}$} & CPAP & $16[32 \%]$ & $12[24 \%]$ & \multirow[t]{2}{*}{0.754} & $12[24 \%]$ & $12[24 \%]$ & \multirow[t]{2}{*}{1.00} \\
\hline & Nasal & $34[68 \%]$ & $38[76 \%]$ & & $38[76 \%]$ & $38[7$ & \\
\hline \multicolumn{2}{|l|}{ Time before initiation of feeding } & $39.66[ \pm 4.7]$ & $26.72[ \pm 3.68]$ & $0.001^{*}$ & $26.72[ \pm 3.68]$ & $26.56[ \pm$ & 0.906 \\
\hline \multicolumn{2}{|l|}{ Days of hospitalization } & $7.36[ \pm 1.28]$ & $3.78[ \pm 1.25]$ & $0.005^{*}$ & $3.78[ \pm 1.25]$ & $3.35[ \pm 1.05]$ & 0.808 \\
\hline
\end{tabular}

Table [7]: Data of Electrolytes after administration

\begin{tabular}{|c|c|c|c|c|c|c|}
\hline & \multicolumn{3}{|c|}{ Group A Compared to group B } & \multicolumn{3}{c|}{ Group B Compared to group C } \\
\cline { 2 - 7 } & Group A & Group B & P value & Group B & Group C & P value \\
\hline K 4h & $4.47 \pm[0.42]$ & $3.75 \pm[0.3]$ & $<0.001^{*}$ & $3.75 \pm[0.3]$ & $3.77 \pm[0.26]$ & 0.447 \\
\hline K 8h & $4.46 \pm[0.41]$ & $3.92 \pm[0.5]$ & $<0.001^{*}$ & $3.92 \pm[0.5]$ & $3.71 \pm[0.29]$ & 0.443 \\
\hline
\end{tabular}

\section{DISUCSSION}

The TTN is due to delay in intra pulmonary fluid resorption and it is an important diagnosis with a dilemma of therapy in NICU, the most common clinical presentation of TTN is tachypnea, which presents during the first and second hours after birth. Breathing can reach up to $60-120$ breath/minute[6].

The inability of the fetal lung that switch trans epithelial liquid flow from secretion to absorption at birth. and the fact that increase in $\mathrm{ENaC}$ expression are seen only in late gestation. may play an important role in the development of TTN[7].
Persistent tachypnea can lead to the increase in hospital stay duration, antibiotic therapy, and parent anxiety[8].

Although the common use of beta-2A in treatment of neonatal chest problem in premature infants, few studies recommended the dosage, duration, efficacy and safety of used inhaled beta-2A in the management of neonatal respiratory disease[9].

The primary objective in our study was to assess the efficacy and safety of inhaled salbutamol in reducing tachypnea, oxygen treatment, time of initiation of enteral feeding and hospitalization for infants with transient tachypnea of the newborn. 
This study showed that the duration of tachypnea, hospitalization, oxygen required, and the time of starting enteral feeding were shorter in the salbutamol group than the control group and there is no Significant difference between single and double dose. Moreover, the $\mathrm{FiO}_{2}$ and $\mathrm{PcO}_{2}$ decreased; however, $\mathrm{O}_{2}$ saturation and $\mathrm{PaO}_{2}$ increased over time in the salbutamol group.

Armangil et al.[5] showed that salbutamol can decrease hospital stay duration among neonates diagnosed with TTN and the results are consistent with the findings of this study $[P<0.05]$. The same results have been found by Armangil et al. in relation to salbutamol effects on respiratory rates; however, in this study, no statistically significant differences were observed in this regard [P>0.05].

Mohammadzadeh et al.[10] showed that inhaled salbutamol can significantly decrease the time of oxygen therapy, initiation of feeding and hospitalization. The obtained results are similar with the findings in our study $[P<0.05]$. As the previous studies showed no neonates experienced any kinds of salbutamol side effects[5,10].

Kim et al.[11] reported that inhaled salbutamol can result in decrease duration of tachypnea and subsequently shorter duration of oxygen and antibiotic therapy. However, no significant reduction in the hospitalization was observed.

In the present study, a significant decrease was observed in the hospitalization in the salbutamol group [P<0.001]. Mousavi et al.[12] showed that administration of salbutamol can result in the significant reduction of respiratory distress score which was consistent with the results obtained from this study $[\mathrm{P}<0.05]$.

In the aforementioned study, the final amount of $\mathrm{PCO}_{2}$ in the case group increased; however, it was not significant. In the present study, this amount had significantly decreased in the case group $[P<0.05]$

Conclusion: The administration of Inhaled salbutamol was effective with respect to both clinical and laboratory findings of TTN and without any adverse side effect. The administration of salbutamol can significantly improve TTN. It reduces the time of hospitalization, the day of initiation the enteric feeding, and the duration of tachypnea. Further studies examining a larger number of patients with strict control over dosage and frequency of salbutamol inhalations are necessary to better direct the treatment of TTN.

\section{Financial and Non-Financial Relationships and Activities of Interest}

None

\section{REFERENCES}

1. Eghbalian F, Sabzehei MK, Emamzadeh N, Shokouhi M, Basiri B, Faradmal J, Salavati J. Comparison of Restricted Fluid Volume with Standard Fluid Volume in Management of Transient Tachypnea of the Newborns: A Randomized Controlled Trial. Int J Pediatr. 2018;6[9]: 8289-96. [DOI: 10.22038/IJP.2018. 30462.2677].

2. Pramanik AK, Rangaswamy N, Gates T. Neonatal respiratory distress: a practical approach to its diagnosis and management. Pediatr Clin. 2015;62[2]:453-69. [DOI: 10.1016/j.pcl.2014.11.008].

3. Andrzejowski P, Carroll W. Salbutamol in paediatrics: pharmacology, prescribing and controversies. Arch Dis Child Educ Pract Ed. 2016;101[4]:194-7. [DOI: 10.1136/ archdischild-2014-307285].

4. Armangil D, Yurdakök M, Korkmaz A, Yiğit Ş, Tekinalp G. Inhaled beta-2 agonist salbutamol for the treatment of transient tachypnea of the newborn. J Pediatr. 2011; 159 [3]: 398-403. [DOI: 10.1016/j.jpeds.2011.02.028].

5. Moresco L, Bruschettini M, Cohen A, Gaiero A, Calevo MG. Salbutamol for transient tachypnea of the newborn. Cochrane Database Syst Rev. 2016;(5):CD011878. [DOI: 10.1002/14651858].

6. Davies JC. Ion transport in lung disease. Pediatric pulmonology. Supplement. 2004; 26: 147. [DOI: 10.1002 / ppul.70087].

7. Harding R, Hooper SB. Regulation of lung expansion and lung growth before birth. J Applied Physiol. 1996; 81 [1]: 209-24. [DOI:10.1152/jappl.1996.81.1.209].

8. Patel H, Gouin S, Platt RW. Randomized, double-blind, placebo-controlled trial of oral albuterol in infants with mildto-moderate acute viral bronchiolitis. J Pediatr. 2003; 142 [5]: 509-14. [DOI: 10.1067/mpd.2003.196].

9. Mohammadzadeh I, Akbarian-Rad Z, Heidari F, Zahedpasha Y, Haghshenas-Mojaveri M. The effect of inhaled salbutamol in transient of tachypnea of the newborn: a randomized clinical trial. Iranian J Pediatri. 2017; 27[5]. [DOI:10.5812/ijp.9633].

10. Kim MJ, Yoo JH, Jung JA, Byun SY. The effects of inhaled albuterol in transient tachypnea of the newborn. Allergy Asthma Immunol Res. 2014 Mar;6(2):126-30. [DOI: 10.4168/aair.2014.6.2.126].

11. Mussavi M, Asadollahi K, Kayvan M, Sadeghvand S. Effects of nebulized albuterol in transient tachypnea of the newborn a clinical trial. Iranian J Pediatr. 2017; 27(3): e8211. [DOI: 10.5812/ijp.8211]. 